\title{
Marginalidad del artista y reivindicación cosmopolita. León de Greiff lee a François Villon
}

En el presente artículo se hace un estudio de la apropiación intertextual que el escritor colombiano de principios del siglo XX hace de la obra del poeta medieval François Villon. El artículo busca señalar la novedad que esta recuperación intertextual significa dentro de la historia de la literatura hispanoamericana, particularmente en el contexto de finales del modernismo. En un segundo momento, se hace un análisis formal del diálogo entre estas dos obras y se señala la obra villonesca como un intertexto fundamental para la construcción de la poética greiffiana. Recurriendo a las propuestas de Linda Hutcheon, interpretamos la "reactualización" de la figura de Villon como una estrategia que le permite a de Greiff hacer una reflexión sobre la condición marginal del artista moderno. Para ahondar en esta problemática recurrimos también a los planteamientos sobre las "máscaras democráticas" propuestos por Ángel Rama. En una última instancia, siguiendo algunas propuestas de Mario Siskind, proponemos interpretar la asimilación greiffiana de este poeta medieval como una estrategia de reivindicación cultural que se enmarca dentro del reclamo latinoamericano de acceder a ese espacio "cosmopolita" y abarcador de la "Literatura Mundial".

Una de las características fundamentales de la obra del poeta colombiano León de Greiff (1895-1976) es la de su asimilación creativa y sincrética de diversas fuentes literarias que, como reconoce Eduardo Gómez, "van desde los juglares medievales hasta los románticos, los simbolistas, parnasianos y modernistas" (166), pero que también incluye elementos provenientes del pensamiento oriental y de mitologías germánicas y nórdicas señaladas por críticos como Humberto Bronx, Fernando Charry Lara y Orlando Mejía Rivera. Esta poética de la asimilación y su deseo de establecer diálogos con distintas tradiciones literarias y culturales tiene, en su caso, un origen claramente modernista pues se deriva de ese cosmopolitismo defendido por escritores como Rubén Darío, José Asunción Silva y Eduardo Gómez Carrillo. Ahora bien, aunque la pretensión de estos últimos era la de entroncar con la corriente amplia de la tradición universal, resulta interesante observar - como ya lo hizo en su momento Baldomero Sanín Cano - que el círculo de lecturas de algunos de 
los modernistas se limitaba a un canon de autores preferentemente franceses que abarcaba, grosso modo, a los poetas simbolistas, decadentes, parnasianos y a las obras críticas de autores como Remy de Gourmont. León de Greiff retoma este impulso modernista de construir puentes de conexión con la corriente amplia de la tradición universal y expande su arco de curiosidad incorporando autores y textos que, hasta entonces, se hallaban fuera del canon literario configurado por sus predecesores modernistas. Esto es lo que sucede, por ejemplo, con su asimilación de la tradición medieval y su rescate de la figura de François Villon. ${ }^{1}$ En el presente artículo me concentro, precisamente, en hacer una lectura de la apropiación greiffiana de la obra de este poeta del siglo XV. Quiero enfocar mi estudio alrededor de dos cuestiones fundamentales. La primera de ellas es la configuración intertextual de algunos de los textos greiffianos que se basan en la lectura del autor medieval francés. La segunda es contextualizar la apropiación y actualización de la obra de Villon en el ámbito de la primera mitad del siglo XX latinoamericano. En esta segunda instancia intento dar respuesta a la siguiente pregunta: ipor qué un autor latinoamericano moderno se esfuerza por recuperar y actualizar la poesía de un poeta tan alejado de sus circunstancias históricas? ¿Cuál es la importancia de esta primera asimilación de Villon en la literatura latinoamericana?

EL LEGADO LITERARIO DE VILLON

El poeta colombiano es, en rigor, el primero que en el ámbito de las letras hispánicas recupera y aprovecha creativamente el legado de Villon. Esta afirmación resulta sorprendente, sobre todo, si se considera que para inicios del siglo XX el poeta francés ya había cobrado una definitiva importancia en la formación de la literatura moderna. Con el fin de justificar esta afirmación y comprender con mayor justeza la importancia de la recuperación greiffiana de Villon, creemos propicio hacer un breve recuento de la recepción de su obra.

Ya en el año 1850 Saint Beuve consideraba afortunada la suerte literaria del poeta medieval Villon. En el artículo que le dedica en sus Causerie du lundi al estudio de Antoine Campaux sobre la obra del poeta medieval, Saint Beuve reconoce dos aportes fundamentales de su obra a la posteridad de la literatura francesa: el primero es el mérito de haber servido de eslabón en una cadena de poetas satíricos que inicia con Rutebeuf y se extiende hasta Rabelais (284). Su segundo legado es la leyenda que se erige alrededor de su obra y de su figura histórica. Nos dice Saint Beuve: "Ce Villon qui avait frisé la potènce ... considéré comme l'un des pères de la poésie, s'est vu à chaque reprise et à chaque rennaissance 
littéraire, recherché des meilleures et salué" (279). El atractivo de su marginalidad y de su condición de "poeta-criminal" le gana la atención de escritores como Clément Marot, Nicolas Boileau y Théophile Gautier (279) quienes recuperan y consagran la obra del poeta medieval. A este primer séquito, habría de sucederle una segunda ola de escritores que observa en el poeta medieval una prefiguración literaria y vital. Los "poetas malditos" de finales del siglo XIX como Verlaine, Baudelaire y Rimbaud encuentran en Villon una anticipación de ciertos rasgos de su estética y su práctica poética, así como también de su actitud de rebeldía frente a lo social. El gesto de ruptura frente a la sociedad y el uso de la poesía como arma de choque son elementos comunes que vinculan la obra villonesca y la de los mencionados poetas de finales del XIX. Luego, ya en la primera mitad del $\mathrm{XX}$, son escritores de corte marcadamente vanguardista como Apollinaire $\mathrm{y}$ Cocteau, quienes habrían de volver la vista para releer y reelaborar esa la leyenda villonesca del "poeta maldito".'

La impronta de Villon ha sido honda y de largo alcance tanto en el ámbito de la literatura francesa como en el de la literatura europea en general. El atractivo y la maleabilidad de su leyenda han permitido que su obra y su biografía sean interpretadas de manera distinta bajo la luz de diversas épocas y varios prismas estéticos. ${ }^{3}$ Es por esta razón que nos llama la atención observar que en el ámbito hispanoamericano la figura de Villon no haya alcanzado el mismo nivel de irradiación que en otras latitudes. A pesar de la relación de estrecha cercanía y el intenso flujo cultural que a partir del modernismo se establece entre los círculos culturales de Francia y Latinoamérica, Villon no cobra en las letras latinoamericanas la misma presencia que otros escritores a quienes este sirve de modelo precursor, como es el caso de Verlaine.

Uno de los primeros libros en los que subrayamos algunas de las escasas menciones al poeta medieval es Los raros. Al trazar el perfil de Verlaine, Darío llama a este último: "hermano de Villon" (59). Enseguida, su descripción pasa a recordar la descripción que Enrique Gómez Carrillo hace del mismo Verlaine: "Sus labios gruesos que se entreabren para recitar con amor las estrofas de Villon o para maldecir contra los poemas de Ronsard" (Darío 55). Las referencias al poeta del "Testamento" son, como vemos, apenas marginales y sirven como término de comparación para caracterizar y vincular al verdadero protagonista de este medallón. Villon aparece aquí apenas como una figura lejana, como una suerte de curiosidad medieval.

Llama la atención que un poeta como Darío, tan buen conocedor de la tradición francesa, o un cronista y erudito como el mismo Gómez Carrillo no hayan dedicado una mayor atención a este poeta que se sitúa al inicio 
de esa línea de "marginales" en la que se inscriben Baudelaire y Verlaine. Dos posibles explicaciones podrían ofrecerse para justificar esta falta de interés. La primera de ellas es el hecho de que la poesía y la leyenda de Verlaine, en lugar de dirigir la atención hacia su antecesor medieval, probablemente hayan logrado eclipsarlo. La segunda explicación resulta un poco más compleja: Si Verlaine ejercía un atractivo como "marginal" este se hallaba lejos de los excesos y los crímenes que dieron fama a aquel otro. La marginalidad del poeta de Fêtes galantes era la de un esteticismo que se contraponía a la filosofía utilitaria y a la "prosa del mundo". Esta fue, precisamente, la actitud que sedujo a los modernistas: el alejamiento de la esfera de lo social por medio del arte, y no el ataque frontal en contra de ella que hallamos en la figura del "poeta-criminal" de Villon. Como nos recuerda Ángel Rama, en el campo de la cultura literaria latinoamericana de la primera mitad del siglo XX se abrieron dos vías de respuesta frente a la expansión del capitalismo y la consecuente marginación del artista durante la primera mitad del siglo XX. Estas dos opciones fueron: 1) la del "negativismo", iniciada por Baudelaire, que "se intensificó por el camino de los llamados poetas malditos"; y 2) la de los "turrieburnistas" cuyo distanciamiento de lo real se efectuaba por medio de un encierro aristocrático en los territorios del arte (Rubén Darío 21). Darío, sentando un precedente para la mayoría de los modernistas que vendrían después de él, se decide por esta segunda vía y rechaza embarcarse en la batalla de confrontación agresiva y directa con la sociedad.

Una de las críticas que se le hizo a Darío tras la publicación de su libro Azul, fue el de su pretendido "galicismo mental" (cit. por Siskind 226). El juicio que Juan Valera escribiera en 1888 se convirtió posteriormente, con algunas transformaciones y adiciones, en uno de los argumentos de ataque más frecuentes en contra de los modernistas. El reproche de Valera no resultaba infundado y hasta el mismo Darío hacía gala de su inclinación por la literatura francesa en textos como "Los colores del estandarte", donde describe como método de composición la ya conocida sentencia "pensando en francés y escribiendo en castellano" (cit. por Siskind 226). Una aclaración sobre este "galicismo" es, sin embargo, necesaria. Tanto el propio Darío como sus detractores confieren a esta palabra un significado bastante reducido y preciso: denotan con ella la adhesión a un específico grupo de autores franceses parnasianos y decadentes de finales del siglo XIX en el que se cifraba el espíritu literario francés de la época. Catulle Mendès, François Copée, Paul Verlaine, Théophile Gauthier, Victor Hugo, y algunos otros formaban parte de esta suma de "lo francés". Por fuera quedaban, pues, a ojos de los poetas modernistas y sus críticos, aquellos otros nombres que entraban en disonancia con la unidad de ese conjunto. 
La crítica más pertinente de este fenómeno fue la que Sanín Cano levantó en su ensayo "De lo exótico" - publicado en 1894 - en la que sanciona la artificialidad y la estratégica reducción acomodaticia de estas categorizaciones literarias nacionales. Si de componer una visión homogénea de la tradición francesa se tratara, sugiere Sanín Cano, "tendríamos, pues, para rato si nos pusiéramos a eliminar nombres" (178). El crítico colombiano condena con dureza esa estrechez de miras que se limita con una penetración superficial de la tradición francesa. "El colmo de estas desdichas," dice en su ensayo, "es que talentos como el de Rubén Darío, y capacidades artísticas como la suya, se contenten, de lo francés con el verbalismo inaudito de Victor Hugo, o con el formalismo precioso, con las verduras inocentes de Catulle Mendès. Francia sola da para más, para muchísimo más" (186). Sanín Cano no pone en cuestión el "galicismo mental", sino la versión reducida y superficial que se instala como norma en las letras hispánicas. De manera indirecta y con casi veinte años de distancia, de Greiff responde a ese reclamo de Sanín Cano, que llama a explorar "más allá." El campo de lecturas greiffiano, aunque todavía se encuentre apegado en sus inicios a las obras de parnasianos y simbolistas, comienza a penetrar en territorios alternativos, reconfigurando y poniendo en cuestión la coherencia de esa imagen de Francia fabricada por los modernistas. El mapa de lo explorable y lo asimilable dentro del corpus de la literatura francesa deviene, en la obra del colombiano, un espacio más grande y se abre hacia territorios en donde de Greiff encuentra elementos fundamentales para la construcción de su propia poética. Su rescate y apropiación de la obra de François Villon responden, precisamente, a ese movimiento expansivo y de exploración que comienza a desbordar los límites trazados por sus antecesores latinoamericanos y que reconfigura el mapa de relaciones con la tradición literaria que se extiende en su obra hasta las fuentes medievales de la literatura francesa.

La aparición de los primeros volúmenes de poesía de León de Greiff marca la primera apropiación significativa de la obra de Villon en la literatura hispanoamericana. En dos de sus poemarios - Libro de signos (1930) y Prosas de Gaspar (1937) - la figura del escritor medieval ya ocupa un lugar de considerable importancia. Es interesante observar que estas dos publicaciones se adelantan en algunos años a la primera traducción al español de la poesía de Villon, realizada por María Héctor en el año 1940 y publicada por la editorial Yunque de Barcelona. ${ }^{4}$ Antes de estas fechas, el nombre de Villon - salvo menciones tangenciales como la ya aludida referencia hecha por Darío en Los raros - resultaba poco conocido dentro de los círculos literarios e intelectuales hispanoamericanos. Es interesante notar, por otro lado, que a pesar de que las primeras menciones a Villon 
aparezcan en su segundo libro, publicado en 1930, el conocimiento que el colombiano tiene de su obra se remonta, por lo menos, hasta la segunda década del siglo XX. En el archivo de su biblioteca personal conservado en la Biblioteca Pública Piloto de Medellín es posible efectuar un rastreo y un tentativo ordenamiento cronológico de algunas de las lecturas de León de Greiff. Los libros de Villon que se conservan como parte de la colección personal greiffiana son dos: Le Testament, publicado por la editorial parisina La Sirène en 1918, y Poésies Complètes publicado por René Hilsum en 1931 - este último lleva la firma de León de Greiff y una fecha escrita en la primera página: abril 1933-. A juzgar por las fechas de publicación y por algunas anotaciones a mano realizadas por de Greiff, podemos tener seguridad de que ya durante las décadas del $20 \mathrm{y}$ del 30, el escritor colombiano tenía una familiaridad y un vivo interés por la obra de Villon. Este interés, dicho sea de paso, habría de mantenerse a lo largo de varias décadas, como puede comprobarse al revisar los materiales que sobre la obra del poeta francés hallamos en su archivo: un estudio de Marcel Schwob, Melanges d'histoire litteraire et de linguistique - L'argot - Villon Rabelais, publicado en 1928; el volumen de Frederic y Leon Saisset Leon, Le Grand Testament de François Villon, de 1937; y esa suerte de novela popular escrita por Patrick Toussaint, François Villon et les dames du temps jadis, publicada en 1959.

APROPIACIONES DE VILLON EN LA OBRA DE LEÓN DE GREIFF

Aunque algunos críticos han venido señalando con insistencia la presencia de la obra de Villon en la poesía de León de Greiff (Fernando Charry Lara, Eduardo Gómez y Sergei Goncharenco mencionan esta relación de influencia), ninguno de ellos ha llevado a cabo un análisis detallado sobre este aspecto. Al igual que con otras fuentes de la poesía greiffiana, sus lectores se han limitado a una enumeración superficial de sus fuentes y han dejado de lado una interpretación comprensiva de su diálogo con otras tradiciones literarias. Es por esta razón que tanto en su aspecto textual como en su significado contextual, la lectura de la apropiación greiffiana de Villon se encuentra todavía en un estado inicial. Es por este motivo que nuestra interpretación se encamina por una vertiente doble. Por un lado queremos hacer un primer acercamiento a la apropiación intertextual greiffiana de ciertas composiciones y formas poéticas retomadas del poeta francés. Por el otro, queremos subrayar su recuperación de la leyenda de "poeta maldito" para observar en ella una reivindicación greiffiana del artista como figura marginal.

La asimilación textual de Villon puede señalarse en un plano general y precisarse en un texto específico. En el plano general es de observar la 
coincidencia en el uso de la "balada" como forma poética. Villon es, junto con Charles d'Orleans, quien en el siglo XV aparece como maestro de esta forma. Tanto en sus "Testamentos" como en el resto de su obra Villon recurrió de manera extensa y casi exclusiva al uso de esta forma. La "Balada de los ahorcados", la "Balada para rezar a nuestra señora", y su "Balada de las damas de antaño" son ejemplos de consagración de este esquema de composición. Tres siglos más tarde, Paul Verlaine - siguiendo a Théodore de Banville en sus Trente-six Ballades joyeuses - retoma esta forma medieval para darle una nueva vigencia y adaptarla al lenguaje de su época. Dentro de la tradición lírica medieval francesa, la balada se estructura, a grandes rasgos, como una composición dividida en tres estrofas de ocho versos, el último de los cuales es el elemento repetitivo del estribillo. Las baladas culminan con una estrofa adicional de cuatro versos, conocida como "envío", que consiste generalmente en una dedicatoria. En la obra greiffiana encontramos un significativo número de composiciones que buscan acercarse a este modelo francés. En Tergiversaciones señalamos un total de dieciocho baladas; ocho en Libro de signos; doce en Fárrago; y una más en Vieja et Novísima. Aunque no en todas estas baladas de Greiff se apega con entera fidelidad al modelo - en muchas de ellas la voluntad de deformación paródica se manifiesta en un trastrocamiento del número de los versos, las estrofas, la posición del estribillo y la extensión del envío -, el recurso a esta estructura poética es significativamente frecuente en su poesía.

Ahora bien, si la balada es asimilada como una herramienta genérica, nos queda por señalar uno de los textos paradigmáticos de intertextualidad villoniana en la obra greiffiana. Este texto es el "Poema equívoco del juglar ebrio", que se propone como una imitación irónica de la bien conocida "Ballade des dames du temps jadis". En este diálogo poético, de Greiff deja de lado una imitación formal y no recurre a la estructura de la balada. Los elementos que retoma del poema de Villon son: 1) el tópico del ubi sunt y 2) la complementaria herramienta retórica del estribillo. Inclinándose por una reelaboración irónica y subjetiva del texto original, el "poema equívoco" puede comprenderse a partir de la definición que Linda Hutcheon hace sobre el fenómeno de la parodia, y que expone como "a form of repetition with ironical distance, marking difference rather than similarity" (6). Una lectura contrastada de los dos poemas hace evidente la distancia y los puentes que se tienden entre ellos.

\begin{tabular}{|l||l|}
\hline Dites-moi où, n'en quel pays, & “Dígasme tú, Villón! Dígaslo tu Lelián! \\
Est Flora la belle Romaine, & o dígalo el mesmo preste Johann: \\
Archipiades, ne Thaïs, & ¿dó están las hermosas que ídose han? \\
\hline
\end{tabular}




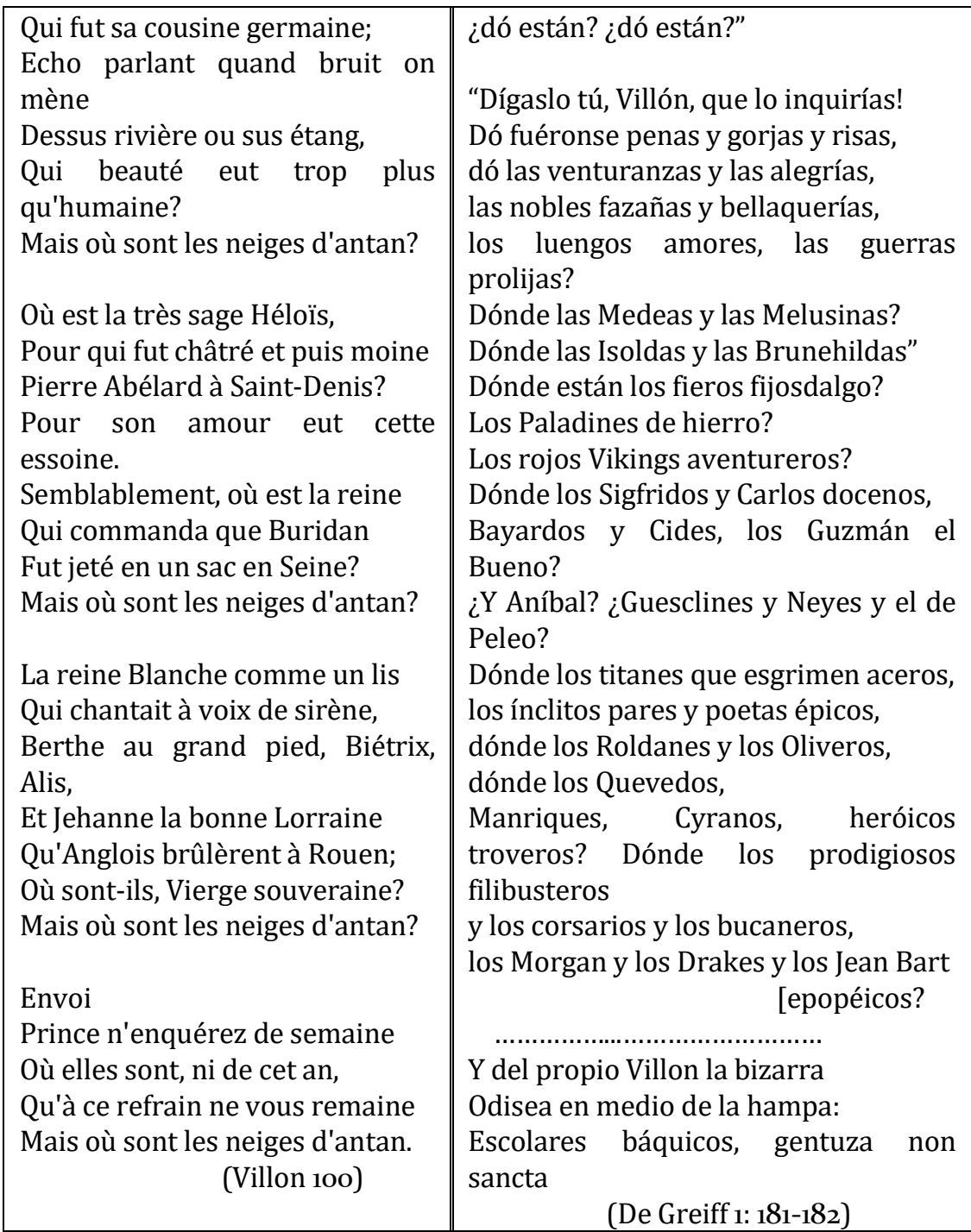

Los puntos de semejanza saltan a la vista: el recurso al vocativo, la enumeración, el uso del estribillo interrogativo. Pero mientras el primero se lamenta por la pérdida de la belleza y los valores nobles simbolizados en Heloïs, la reina Blanche y Juana de Arco, el poeta colombiano trastoca el tópico del ubi sunt y levanta una afectada queja por la pérdida de elementos de muy distinta naturaleza. El verso “¿dó están las hermosas 
que ídose han?" aparece apenas como un guiño retórico al poeta medieval, luego del cual comienza su reelaboración individual del poema. De Greiff pone en fila una serie de personajes que, en su conjunto, pueden ser leídos como una presencia simbólica de los valores cuya desaparición es motivo de aflicción para la voz poética. Más que en su significado individual, el poema construye redes que apuntan hacia una configuración de "tipos" o "ideas". Desde esta perspectiva, el lamento por la pérdida de Medeas, Melusinas, Isoldas y Brunehildas, debe ser interpretado teniendo en cuenta el rasgo común que vincula a estas cuatro figuras: la dimensión mítica o legendaria. En el caso de las menciones a Roldán, Oliveiro, el Cid y Bayardo, se dirige hacia la construcción de un arquetipo de héroe épico. De otra parte, los vikingos, Morgan y Drake, se reúnen bajo el signo común del espíritu de aventura y el paradigma del viajero. Finalmente, el último "tipo" que aquí aparece es el del poeta, sintetizado en las figuras de Manrique, Cyrano y, evidentemente, el mismo Villon. Si reducimos a estos cuatro paradigmas representativos toda la serie de personajes enumerados, podemos adelantar la siguiente hipótesis de lectura. El tópico del ubi sunt que de Greiff retoma de Villon se convierte en un recurso para cuestionar ya no la desaparición de la belleza y meditar sobre la fugacidad del tiempo, como sucede en Villon, sino para lamentarse por la pérdida de una imagen del mundo.

Este recurso intertextual al que apela de Greiff pone en diálogo elementos de la tradición poética de finales de la Edad Media europea, con el contexto histórico en el que se inscribe su propia obra. Con esto, no sólo le confiere una nueva vigencia al texto villoniano sino que, como sugiere Hutcheon sobre la función de la parodia, al inscribir el pasado en el presente, transforma este recurso en una herramienta de observación y de juicio sobre su propio tiempo, a la vez que "embod(ies) and bring(s) to life actual tensions" (xii). El "dónde están" greiffiano no es sólo una herramienta retórica sino, y sobre todo, una pregunta de alta carga significativa que inquiere por la desaparición de una dimensión "mítica" del mundo. Esta pregunta greiffiana cuestiona lo que Max Weber llamó el "desencantamiento" o "desmiraculización del mundo", la pérdida de un sentido de trascendentalidad de la vida (155). Al mismo tiempo, este ubi sunt moderno se puede interpretar como una reacción contra la sociedad positivista, contra la "prosa del mundo" y sus valores antipoéticos que terminan por hacer del artista y del escritor una figura aislada y marginal. Nos encontramos, pues, con una suerte de canto agónico por un mundo que desaparece bajo las presiones de las dinámicas económicas capitalistas, la ideología utilitaria y una filosofía positivista que durante la primera mitad del siglo XX se instalan en los países latinoamericanos. Visto 
desde esta perspectiva, el poema greiffiano no resulta un mero ejercicio de escapismo poético que busca refugio imaginativo en la obra de un poeta del siglo XV. Su toma de distancia no es simplemente un olvido del mundo, sino una toma de posición frente a su realidad histórica. La recuperación de este poema medieval debe entenderse bajo la misma óptica que adopta Hutcheon para comprender la parodia moderna: como una estrategia textual de auto-reflexividad (2).

Además de sus apropiaciones textuales de la obra de Villón, León de Greiff reinterpreta su leyenda de "poeta maldito" creando un personaje poético que reaparece en varios momentos de su obra literaria. De Greiff crea este personaje como una suerte de espejo ideal en el cual busca ver proyectados los rasgos de su personalidad poética. Al construirse un Villon que se ajusta puntualmente a las características del "poeta maldito"y que se sitúa como antecesor de esa línea de poetas marginales y rebeldes que incluye a Verlaine, Rimbaud y Baudelaire, el poeta colombiano está buscando crear retrospectivamente la imagen de su propio predecesor en el cual halla prefigurada la doble valencia de su naturaleza poética que oscila entre el hombre de letras y el personaje aventurero. De Greiff se fabrica un Villon muy a su manera, presentándolo como una estampa de poeta pícaro, bohemio, criminal, hedonista, que transita con igual facilidad entre el ámbito erudito de la Sorbona y el espacio popular de la calle. Al resaltar esa doble naturaleza de culto y vulgar, de Greiff busca configurar su propio reflejo. Este juego de espejos gana una expresión clara en el número XVIII de las Prosas de Gaspar, en donde, mediante el uso recurrente de la analogía y la comparación, se subraya ese deseo de identificación:

Escolar fui, como él, y como él, de la Sorbona. Escolar de la Sorbona, amén de muy ducho esgrimidor y duelista, así como insigne trasegador de vinos diversos, renombrado catador de finas viandas en los más famosos figones, y no menos renombrado sofaldador de doncellas ... urdidor de befas de toda índole, no bien inocentes todellas... (De Greiff 1: 295)

Ahora, si bien es verdad que, como lo recuerda Jane Taylor, "we construct our own particular Villons, of course, by reading very selectively" (1), en el caso greiffiano podría decirse que este proceso de construcción va todavía un paso más allá. La lectura que el colombiano hace de Villon resulta una apropiación creativa no sólo por la asimilación individual y actualización del texto que supone cualquier lectura - como lo han subrayado con insistencia los estudiosos de la "teoría de la recepción" - sino porque se 
vale de ella para realizar una autoconstrucción biográfica ficticia y elaborarse una original máscara poética.

Esta configuración de la "máscara" merece un comentario detallado. En el conjunto de textos reunidos bajo el título de Máscaras democráticas del modernismo, Ángel Rama hace un estudio bastante agudo sobre la lógica de la "representación" y el fenómeno de la proyección objetiva del deseo en el contexto de la cultura capitalista. El uruguayo observa que el "disfraz" es una suerte de "puesta en escena" que la sociedad moderna adopta como estrategia de configuración identitaria. Siguiendo las ideas de Nietzsche, Rama observa que la sociedad democrática es una suerte de "baile de máscaras" en el cual los individuos construyen "sus propias máscaras de conformidad con las pulsiones del deseo" y al tiempo que proyectan esas "imágenes ficticias" en el plano de lo social, pasan a "representar esos papeles, con los cuales soñaban" (Máscaras 88). ${ }^{5}$ Esta es la misma lógica que encontramos operando en varios textos greiffianos y que subrayamos en el poema XVIII de las Prosas de Gaspar. En este texto, de Greiff se confecciona un traje y una reputación a imitación de los de Villon, buscando así afirmar y validar, a través de este proceso imitativo, una cierta identidad poética que se ajusta al paradigma del rebelde hedonista. Sin embargo, la máscara greiffiana no busca una proyección en el dominio social, sino que se cierra dentro de los límites de lo literario. Su intención es la de fabricarse una "personalidad" poética, una "leyenda" a la manera de Villon, para contrarrestar y rectificar el carácter prosaico de lo real.

Considerada de esta manera, la relación con Villon parece nuevamente caer en el dominio del escapismo y encierro en torres de marfil que tanto se les criticó a los poetas modernistas. No obstante, una lectura más profunda de este aspecto nos permite reiterar una de las ideas que Gerard Aching adelanta en The Politics of Spanish American "Modernismo": las manifestaciones de exotismo y distanciamiento modernistas también pueden entenderse como una forma de compromiso (3). Así como el recurso intertextual de la "Ballade des dames du temps jadis" le permite a de Greiff hacer una reflexión sobre su época y la desaparición de la dimensión trascendente del mundo, esta reelaboración de la figura de Villon le permitirá sugerir algunas consideraciones sobre la situación histórica del artista.

La idea que queremos proponer es que de Greiff le concede tan amplia atención a Villon no únicamente por la proyección individual que hace de sí mismo en la figura de aquel, sino porque observa en la marginación de este poeta medieval un reflejo del aislamiento del poeta moderno - que es el suyo propio, y el de los poetas hispanoamericanos de la primera mitad 
del siglo. El poeta colombiano del XX se acerca al del siglo XV porque observa en él a un "camarada", a otro ser "marginal," que se sitúa en las fronteras de la sociedad. Aunque es cierto que, como observa Karl Uitti, "the marginality of the modern artist differs in kind from the marginality of Villon" (149), hay puntos comunes que nos permiten trazar una línea de comparación. En primer lugar, es necesario precisar que la marginalidad de Villon no se debió de ninguna manera a su condición de poeta. Por el contrario, su estatus de letrado hizo que tuviera un trato preferencial en algunos de sus impasses con la ley. Villon fue marginado como consecuencia de los actos criminales que le llevaron a enfrentar una pena de muerte - de la cual sale absuelto - y, luego, el exilio. La marginalidad de poetas como de Greiff fue de signo contrario: no fue el crimen o la infracción de la ley lo que les granjeó esta condición, sino su profesión de "hombres de letras". Como bien observa Ángel Rama, a comienzos del siglo $\mathrm{XX}$ el letrado comienza a convertirse en una figura indeseable dentro del ordenamiento social:

[N]o sólo es evidente que no hay sitio para el poeta en la sociedad utilitaria ... sino que esta, al regirse por el criterio de economía y el uso racional de todos sus elementos para los fines productivos que se traza, debe destruir la antigua dignidad que le otorgara el patriarcado al poeta y vilipendiarlo como una excrecencia social peligrosa. Ser poeta pasó a constituir una vergüenza. La imagen que de él se construyó en el uso público fue la del vagabundo, la del insocial, la del hombre entregado a borracheras y orgías ... esta lucha contra el poeta que orienta la burguesía hispanoamericana ... que no distinguía mucho entre el peligro de un hombre dedicado a la poesía y el de un anarquista con la bomba en la mano (Rubén Darío 57).

En este esquema, el poeta es un elemento "improductivo" y su presencia es percibida como perniciosa. Su inadecuación al modelo lo sitúa al mismo nivel que el de un asocial, un anarquista y muy cerca del criminal. Es aquí donde percibimos el puente que conecta la figura "criminal" de Villon, como la del poeta moderno a quien por cuenta de su falta de "productividad" también se asocia con la de un "indeseable". Las dos figuras representan un desafío y un peligro para el orden económico e ideológico. Desde esta perspectiva, resulta bastante clara la atracción que Villon debió ejercer en de Greiff, por cuanto este resulta una figura doblemente amenazante a los ojos de la sociedad burguesa: es a la vez un artista y un criminal. Recuérdese a este respecto la definición que Octavio Paz hace en El arco y la lira de la figura de los "Los 'poetas malditos", de 
quienes dice "no son una creación del romanticismo: son el fruto de una sociedad que expulsa aquello que no puede asimilar" (232).

Si se tiene en cuenta esta expulsión social del artista señalada por Paz no resulta arriesgado decir que al rescatar la leyenda de Villon y reutilizarla creativamente, el poeta colombiano propone una reflexión sobre la situación del artista en una sociedad que poco a poco se empieza a plegar a las dinámicas de funcionamiento y organización de las sociedades modernas. Aunque más que una reflexión, resulta apropiado hablar de una reivindicación puesto que hay en sus textos una voluntad de compensación simbólica y no una simple consideración abstracta. Si en su vida personal de Greiff optó por trabajos que le permitieran adaptarse a las demandas económicas y productivas de la sociedad - trabajó como funcionario bancario, como administrador en la construcción del ferrocarril en Antioquia y llegó a ocupar un puesto diplomático posteriormente - en su poesía cultiva el ideal del poeta "asocial" y "decadente". El modelo de este "artista maldito" y su personaje se construye en los poemas greiffianos como un paradigma de energía vital, de libertad y de un cierto heroísmo rebelde que contrapesa la infravaloración de la figura del poeta en el plano de lo social. En su "efigie" se celebran los valores que se oponen a las convenciones y la ideología de la sociedad colombiana de su época. Los siguientes fragmentos tomados de dos de sus poemas delinean esa imagen:

Quiero ello sí! La exótica aventura.

Mi viejo amor y el villonil arreo.

Quiero, ello sí la exótica aventura,

Mi viejo amor, mi villonil manteo

("Segunda balada del abominario" I: 148)

...nunca más vi ante mí su desgarbada encarnadura de Judío Errante, la su lacia pelambre azafranada y revuelta ... Ni volví a escuchar su voz plena y jocunda, fácil al gracejo, y aguda y chirriante para la maledicencia, la disputa y el insulto procaz, o cariciosa, asordinada, cálida, para las amatorias lides ... sé de una heroico-bufocómica novela suya, pícara y burlesca, plagada de exquisitas truculencias, de facecias libertinas y drolátricas, y de todo género de truhanerías... ("Prosa XVIII" I: 295-296)

El Villon que se nos presenta en estos dos fragmentos es suma de aventura, errancia, picaresca, burla, erotismo, humor y libertinaje. Su identificación con este estilo de vida resulta tan paradigmática que de Greiff no duda en acuñar el adjetivo "villonil" para referirse a esta vida de tan radical oposición a la norma. La celebración de estos valores rebeldes nos conduce 
a pensar que, a través del "personaje" Villon, León de Greiff busca resacralizar la figura del "poeta" y reintegrarle poéticamente la dignidad que en el plano social se le ha escamoteado. De esta manera, la dimensión textual se afirma como un espacio compensatorio y de reivindicación de la dignidad artística. Retomando algunas observaciones de Rama sobre los poetas que se afirman en su marginación, podría decirse que a través de la figura de Villon, el colombiano "asume la mirada congeladora que le dirige la sociedad como único medio de recuperar una cierta jerarquía de signo contrario" (59). Esta jerarquía de signo contrario significa una irónica recuperación de la "aureola" perdida por el poeta en el contexto de la sociedad moderna. Este fenómeno se realiza, al menos en la obra greiffiana, en el plano textual, donde se efectúa una inversión de jerarquías y valores. La lucha que poetas como Alejandro Sawa - a quien recuerda Rama como ejemplo de "afirmación suicida" de la bohemía - llevan a cabo en el plano social, el colombiano la traslada al terreno poético y le da allí un carácter objetivo en esa celebración irónica de Villon.

DISLOCACIÓN HISTÓRICA Y REIVINDICACIÓN COSMOPOLITA

En las páginas anteriores hemos adelantado una lectura de la apropiación intertextual y de la asimilación de la leyenda de Villón en la poética greiffiana. En estas dos líneas rastreamos la conexión más claramente identificable entre los dos autores. Hay, sin embargo, un último punto que quisiéramos tratar brevemente en este apartado final: el cuestionamiento de los procedimientos que le permiten a De Greiff saltar cinco siglos de diferencia y situarse en un nivel de paridad con el poeta medieval al que llama su "camarada". En su libro Cosmopolitan Desires, Mariano Siskind hace esta observación acerca de la apropiación de literaturas y autores extranjeros por parte de los escritores modernistas: "modernismo's world literary discourse does not invoke foreign literatures to signify otherness but rather views foreign works and authors, in classical cosmopolitan fashion, as distant relatives and kindred spirits whose names signify the presence of a world that includes Latin America" (105).

Este comentario resulta bastante pertinente para comprender la relación que León de Greiff establece con la obra de Villon. Lo que es más, estos apuntes de Siskind podrían servir de comentario a las siguientes líneas de la ya citada "Prosa XVIII": "Mas fui su camarada. Su camarada y algo más; casi su cómplice. Verdad. Podría asegurároslo. ... Claro que sí. Su camarada y casi que su cómplice ... Y os he de decir que no fue asaz pacata ni ejemplar ni heterodoxa mi vida de ésas épocas. Nuestra vida de ésas épocas..." (Greiff I: 294). Mediante este juego de dislocación histórica De Greiff busca difuminar las marcas de diferencia y la distancia cronológica 
que lo separan de Villon, y lo presenta como una figura frente a la cual se sitúa en un estatuto de paridad. Su relación de familiaridad se enfatiza, además, mediante los términos que escoge para referirse a su relación ("camarada", "cómplice"), así como con el uso del posesivo "nuestra" para referirse a esa "heterodoxa" vida común. Este gesto revolucionario llama poderosamente la atención porque resume de manera paradigmática el deseo greiffiano de "ser igual", de "contemporaneizar" con los poetas que, como Villon, forman parte de la tradición europea. Hacemos esta aclaración porque consideramos que en este texto la presencia de Villon no debe leerse como significante unívoco, sino que debe interpretarse como una manifestación representativa del deseo modernista de apertura cosmopolita al mundo y a las literaturas foráneas. Enmarcado en este contexto modernista, el texto greiffiano gana una dimensión significativa bastante más amplia puesto que su reclamo de ser "contemporáneo" de Villon, hace eco de ese deseo continental modernista de reconfigurar las fronteras del mapa cultural mundial y reclamar para la figura del escritor latinoamericano un lugar de igualdad frente a los espacios europeos dominantes. Leído de esta manera, ese texto autoficcional de aparente evasionismo egotista, cobra una resonancia continental al replantear metonímicamente en las figuras de De Greiff y Villon, los términos de relación entre Europa y Latinoamérica. A un nivel textual, el poeta colombiano trata de corregir la asimetría entre centro y periferia que caracterizó hasta principios del siglo XX las relaciones de flujo cultural entre el viejo y el nuevo continente. Así se pueden comprender este poema y el ejercicio intertextual implícito, como estrategias de reivindicación cultural.

Lehman College - CUNY

NOTAS

1 En su ensayo "Villon et Verlaine", Paul Valéry hace un breve recuento de la vida de Villon: "Villon, qui se nomma d'abord François de Montcorbier, naquit à Paris en 1431. Sa mère le remit, trop misérable qu'elle était pour l'élever, aux mains d'un docte prêtre, Guillaume de Villon, qui appartenait à la communauté de Saint-Benoît-le-Bétourné, et y avait son domicile. C'est là que François Villon grandit, reçut l'instruction élémentaire ... À l'âge de dix-huit ans, le jeune homme est reçu bachelier. À vingt et un ans, dans l'été 1452, le grade de licencié lui est conféré. Que savait-il ? Sans doute ce que l'on savait pour avoir suivi, de plus ou moins près, les cours de la Faculté des Arts: la grammaire (la latine), la 
logique formelle, la rhétorique (l'une et l'autre selon Aristote, tel qu'il était connu et interprété en ce temps-là); plus tard venaient quelque métaphysique et un aperçu des sciences morales, physiques et naturelles de l'époque".

2 Son particularmente ilustrativos a este propósito los artículos: "Apollinaire et Villon” de Michel Decaudin, y “Cocteau et Villon” de Pierre Caizergues. Los dos artículos se encuentran recopilados en el volumen Villon et ses lecteurs.

3 La recepción de la obra de Villon fue particularmente afortunada en el ámbito de la literatura inglesa. Michael Freeman hace un recuento de las primeras lecturas de la obra del poeta en el ámbito inglés: en 1835 Luisa Costello lleva a cabo la primera adaptación inglesa; en 1847 aparece la versión de Henry

Francis Cary; en 1870 es el mismo Dante Gabriel Rossetti quien se interesa por verter al inglés en una versión prerrafaelista los textos del francés; en 1877 sale a la luz el trabajo de Swinburne; en 1878 se publica la traducción de la obra completa de John Payne. Por otro lado Robert Louis Stevenson le consagra también un ensayo biográfico (François Villon: Student, Poet and Housebreaker) y un cuento ("A lodging for the night"), y el mismo Ezra Pound compone una ópera inspirada en Le Grand Testament. En el ámbito germánico, Bertold Brecht asimila de forma creativa la figura de Villon en su La ópera de tres centavos.

4 En su tesis doctoral Las traducciones al español de la obra de François Villon: análisis traductológico, Beatriz Martínez rastrea las siguientes traducciones de la obra de Villon: María Héctor, François Villon. Poesía (1940); Alfredo Darnell Gascou, François Villon. Baladas (1946); Antonio de Obregón, Villon, poeta del viejo París (1954); Alberto de la Guerra Navares, François Villon. Baladas completas (1972); Gonzalo Suárez, François Villon. El hombre y el poeta (1974); Federico Gorbea, François Villon. Obra completa en poesía (1976); Mercedes Lloret, François Villon. Poemas (1977); Carlos Alvar Ezquerra, François Villon. Poesía (1980); Roberto Ruiz Capellán, François Villon. Obras (1981); Juan Victorio, François Villon. Poesía (1995); José María Álvarez, François Villon: El Legado y El Testamento (2001); Rubén Abel Reches, Testamentos de François Villon (2007).

5 Me refiero puntualmente a las ideas que Nietzsche expone sobre el proceso de democratización que él comprende utilizando la metáfora de un baile de máscaras. Estas ideas están expuestas en Más allá del bien y del mal. Rama se refiere a ellas en el capítulo III de Las máscaras democráticas del modernismo (8o-87). 
OBRAS CITADAS

ACH IN G, GERARD. The Politics of Spanish American 'Modernismo': By Exquisite Design. Cambridge: Cambridge UP, 1997.

B RONX, HU M B ER T o. León de Greiff: su vida y selección de sus poesías. Medellín: Editorial Salesiana, 1973.

Caizergues, pierre. “Cocteau et Villon”. Villon et ses lecteurs. Actes du Colloque International. Eds. Jean Dufournet, Michael Freeman y Jean Dérens. París:

Champion, 2005. 241-248.

CHARRY LARA, FERNAN D 0. "León de Greiff: la creación de un lenguaje". Revista Eco 188 (1977). 181-192.

DARío, RUBÉN. Los raros. Madrid: Editorial Mundo Latino, 1917.

DE GRE IF F, LEÓN DE. Obras completas. Vols. I y II. Bogotá: Tercer Mundo Editores, 1975 .

DECA U D I , M I C H L. "Apollinaire et Villon". Villon et ses lecteurs. Actes du Colloque International. Eds. Jean Dufournet, Jean, Michael Freeman y Jean Dérens. París: Champion, 2005. 207-222.

FRE EMAN, MiChAEL. "L'étrange cas du docteur Stevenson et de Monsieur Villon". Villon et ses lecteurs. Actes du Colloque International. Eds. Jean Dufournet, Michael Freeman y Jean Dérens. París: Champion, 2005. 139-154.

G Ó M EZ, E DU A R D o. "León de Greiff: El lírico contra la lírica tradicional". Valoración múltiple sobre León de Greiff. Santafé de Bogotá: Universidad Central/Casa de las Américas, 1995. 153-168.

gonCharenco, Sergei. "El maestro de lo imposible". Revista Casa Silva 9 (1995). $36-40$

hUtChE ON, Linda. A Theory of Parody. New York: Methuen, 1985.

MARTÍNEZ OJEDA, BEATRIZ. Las traducciones al español de la obra de François

Villon: Análisis traductológico. Dis. Universidad de Córdoba, 2012.

MEJÍA RIVERA, ORLAND O. "La intuición búdica y los heterónimos en León de Greiff". Revista Aleph. 125 (2003). 51-64.

NiETZSCHE, FE DER IC 0. Más allá del bien y del mal. Madrid: Aguilar, 1974.

PAZ, oc ta vio. El arco y la lira. Bogotá: Fondo de Cultura Económica, 1994.

RAMA, Á G G L. Las máscaras democráticas del modernismo. Montevideo: Editorial Fundación, 1985.

—. Rubén Darío y el modernismo. Caracas: Universidad Central de Venezuela, 1970. Saint beuve, Charles a gus tin. Causeries du lundi.Vol. 14. París: Garnier Frères, 1852.

—. Tableau historique de la poésie et du théatre français au XVIe siècle. París:

Charpentier, 1869 .

SA ín CAN O, BALd omero. Ensayos. La Habana: Casa de las Américas, 1964. 
SIS I I D, M AR Io. Cosmopolitan Desires. Global Modernity and World Literature in Latin America. Evanston: Northwestern UP, 2014.

TA YLOR, JANE H. M. The Poetry of François Villon. Cambridge: Cambridge UP, 2001. UI T T I, KAR L. "Villon's 'Le grand Testament' and the Poetics of Marginality". Modern Philology 93. 2 (1995).

VALÉ RY, PA L. "Villot et Verlaine”. Biblisem. La mémoire littéraire et historique l'Occident chrétien. 81. Edición. S. pag. Web.

Villo n, fRA nç o Is. Poesía Completa. Ed. Gonzalo Suárez. Madrid: Colección Visor de Poesía, 2006.

WE B E, M AX. Ensayos sobre sociología de la religión. Vol. 1. Madrid: Taurus, 1984. 